\title{
Kinematic research of closed planetary gears
}

\author{
Ildar Kutlubaev ${ }^{1,2}$, Elena Matcko ${ }^{2}$, and Olga Panfilova ${ }^{1, *}$ \\ ${ }^{1}$ Nosov Magnitogorsk State Technical University. Magnitogorsk, Russia \\ ${ }^{2} \mathrm{JSC}$ «SPA «Android technics», Moscow, Russia
}

\begin{abstract}
The approach to the kinematic research of planetary gears which are closed by nonparallel circuit is represented. The analytical dependencies of transmission ratio on geometric parameters using graphic method are obtained. The obtained dependencies are the basis for power analysis accomplishment.
\end{abstract}

Planetary gears are essential part of modern machines and aggregates. Proven production technology of units and workpieces, ability to achieve high transmission ratios determine their dynamic utilizing. Planetary gears (PG) are used for transmission of rotational torque in the wide range. Planetary gears with the torque above or equal of 5 $\mathrm{Nm}$ are used in drive units of manipulator links, the rotational torque value of travel mechanisms of building, road, and mining machines reaches $500 \mathrm{Nm}$. The high level of toughness, smoothing of errors and gaps are achieved by multizone contact of links that leads to decreasing of backlash play.

Planetary gear production keeps steadily growing [1]. Technologies that realize double-flow construction schemes of PG such as biplanetary [2] and complex [3] are advanced as well as planetary-lantern-wheel schemes. Kinematic schemes and linear velocity drafts of doubleflow PG with complex dog chart and biplanetary gear are represented correspondingly in figures 1 and 2 .

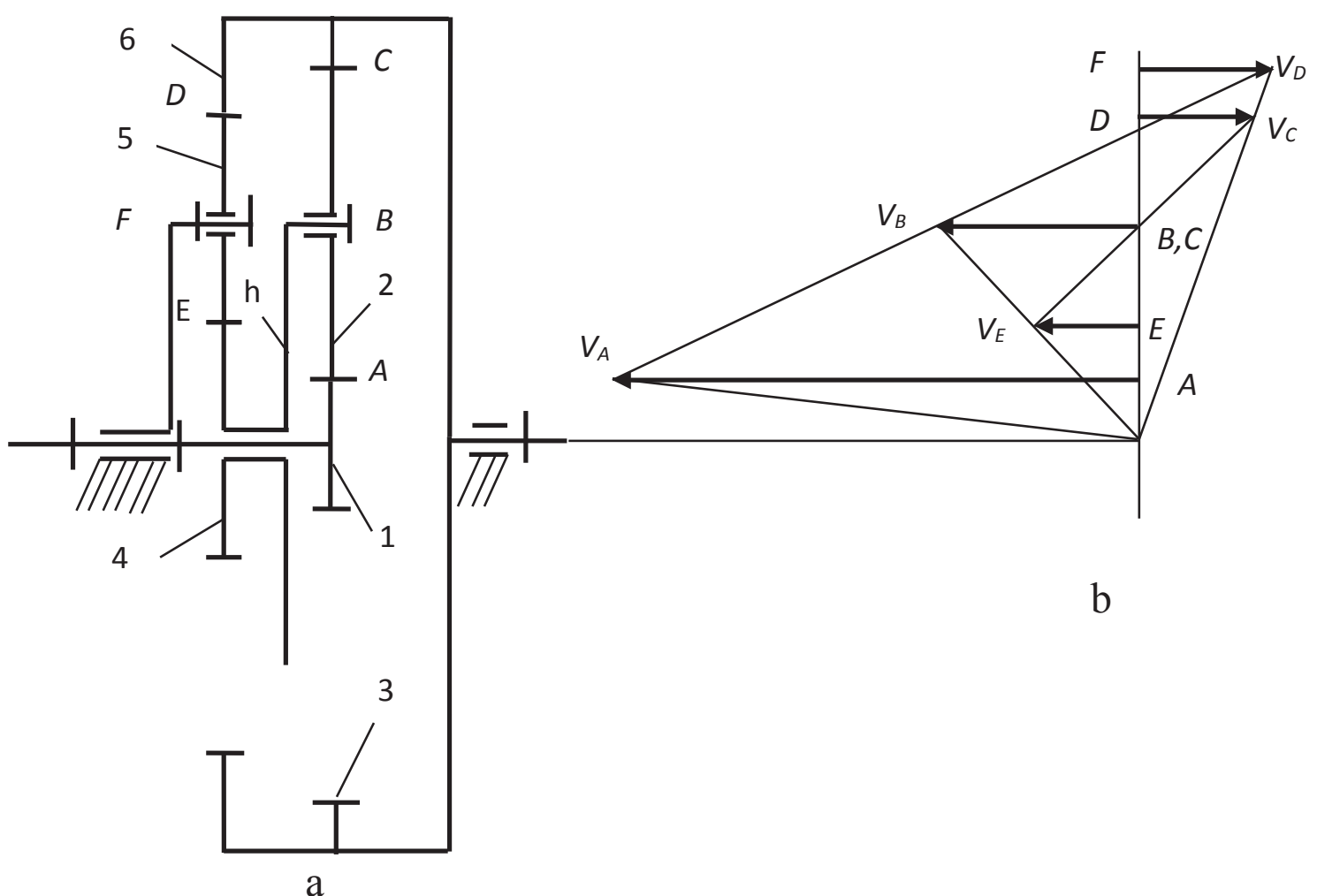

Fig. 1. Kinematic scheme (a) and velocity draft (b) of double-flow PG with complex dog chart

\footnotetext{
* Corresponding author: halikova@inbox.ru
} 


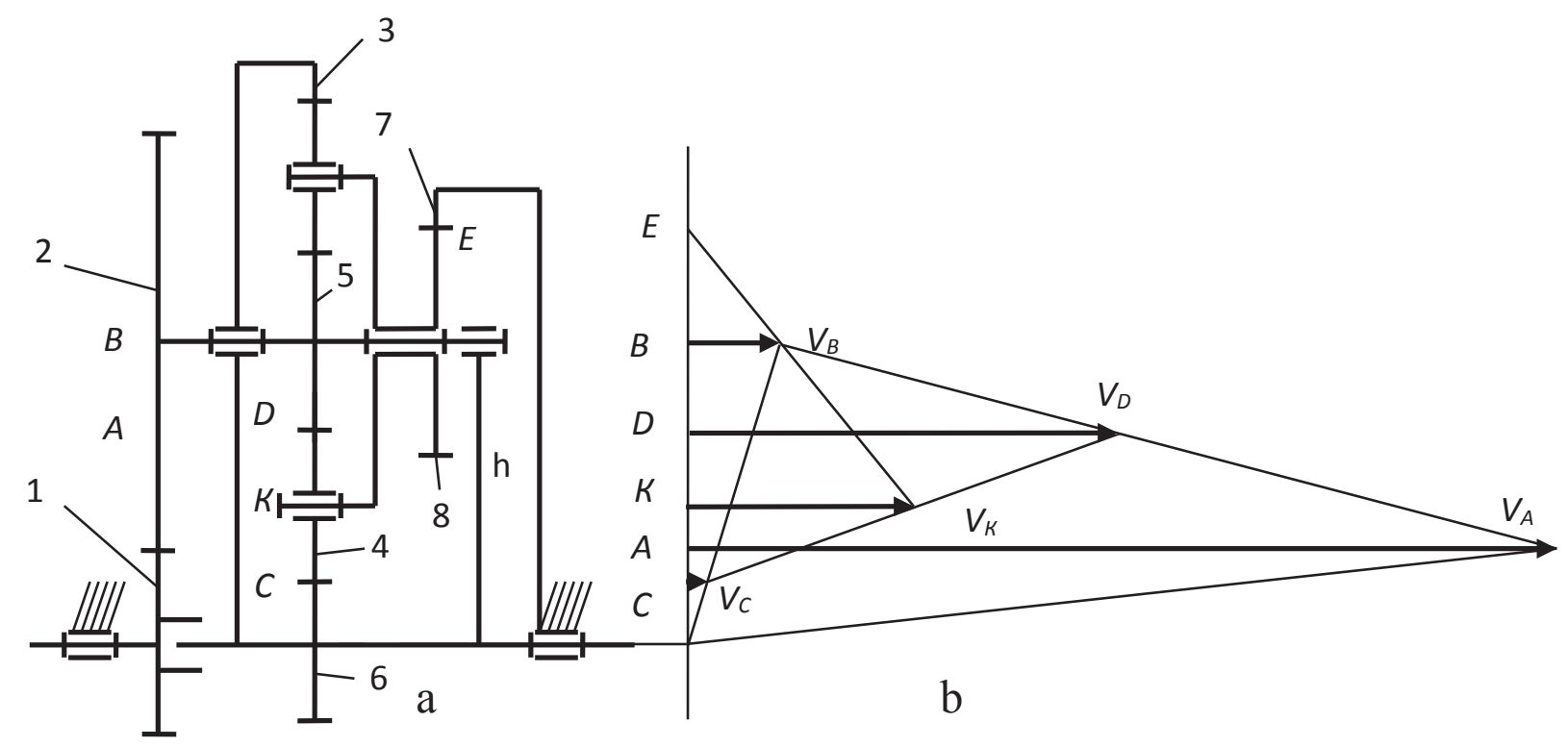

Fig. 2. Kinematic scheme (a) and velocity draft (b) of biplanetary gear

Kinematic chains of represented PGs contain two closed nonparallel circuits. Input power flow falls under two flows in the process of transmission and transformation and after that summarizes in an output link. Transmission of rotational torque through nonparallel flow using tooth gear (figure 1, a) or leverage (figure 2, a) is realized in addition to conventional separation into parallel power flows. This approach decreases load on all tooth wheels and especially on output tooth wheel. As the value of center-to-center distance is determined by transferred torque the separation of rotational torque into two nonparallel flows provides the decrease of transmission size and the additional increase of stiffness.

In a complex scheme (figure 1 , a) the rotational torque is transferred to output link 3 (6) through planetary stair (which includes wheels 1, 2, 3 and carrier h) and regular transmission of wheel: $4,5,6$. At the same time the output link consists of fixedly connected wheels 3 and 6 .

In biplanetory gear (figure 2, a) the axle is output and wheel 6 and carrier $h$ are fixedly mounted on it.

It should be noted that closed gears with transmission of several rotational torque flows from two or more input links to one output link are realized [4].

The kinematic research of accepted construction scheme that is presentation of the gear transmission ratio as function of geometric parameters (numbers of teeth) is the foundation of drive unit designing. In relation to PG the research is accomplished on the basis of Willis formula or graphic method. The reversed motion method in regard to closed PG is quite difficult [4]. With the advent of graphic editors graphic methods become more popular in consequence of visibility and simplicity of finite dependences obtainment [5-7].

However the current sequence of construction of velocity diagram starting from the guide link is not workable for closed gears represented in figures 1,2 . It is connected with the fact that the link that engages with the guide link requires the initial information regarding velocity of its two points. Thus complex scheme requires information regarding velocity of points $\mathrm{A}$ and $\mathrm{C}$ (or $\mathrm{B}$ ). However only A point velocity is known (given).

Biplanetory gear requires information regarding velocity of points $A$ and $B$ similarly. In such a case only A point velocity is known (given).

The goal of the research performed was the development of approach to determination of transmission ratio of closed PG using graphic method.

The objective of research was obtainment of analytic forms of transmission ratio by geometric parameters by the example of two variants of closed PG.

Kinematic analysis accomplishment in the reverse order (from the output link to the input link) is the basis of the approach. On the basis that links of both flows lock in on output link it appears that linear velocities of links which contact it are certain. This makes it possible to use velocities of two points within each flow of power transmission for kinematic analysis.

In relation to double-flow PG closed by tooth wheels (figure 1, a) the analysis is performed in the following order. Velocity diagram of output link is drawn according to the adopted angular velocity of wheel 3 (6). Then linear velocities of points $C$ and $D$ are determined on basis of this diagram. Point E velocity is determined for the wheel 5 according to pints $\mathrm{D}$ and $\mathrm{F}$. Velocity diagram of the wheel 4 (carrier $\mathrm{h}$ ) is drawn according to the point $\mathrm{E}$ velocity. That makes it possible to determine linear velocity of point $B$ that is mutual for carrier $h$ and wheel 2.

As a result velocities of two points (C and $\mathrm{B})$ of wheel 2 are discovered that makes it possible to draw its velocity diagram and determine velocity of point A of input link.

Transmission ratio of a given type planetary gear is determined according to the velocity diagram by means of simple geometrical correlations.

$$
u_{13}=2 \cdot \frac{d_{6} \cdot\left(d_{1}+d_{2}\right)}{d_{4} \cdot d_{1}}+\frac{d_{3}}{d_{1}}
$$


di - diameters of $\mathrm{i}$ wheels.

In biplanetory gear locking of flows on an output link is performed by tooth wheel 7 and carrier h, that is PG with wheel-leverage locking. Kinematic analysis is performed in the following order. Velocity diagram of the output link is drawn and velocities of point $\mathrm{E}$ (wheel 7), axis of carrier $\mathrm{B}$ and point $\mathrm{C}$ are determined according to the adopted angular velocity of wheel 7 (carrier h). Velocity diagram of the wheel 8 is drawn and velocity of point $\mathrm{K}$ is determined according to known velocities of two points of wheel 8 (E and B).

Velocity diagram is drawn and velocity of point $\mathrm{D}$ is determined on the ground of linear velocities of two points of wheel 4 ( $\mathrm{C}$ and $\mathrm{K})$. That makes it possible to draw velocity diagram of 5-2 wheels according to velocities of two points (D and $\mathrm{B}$ ) and to determine linear velocity of point A.

Diagram of possible velocities (figure 2, b) is drawn in concordance with the outlined order.

Velocity diagram makes it possible to determine transmission ratio of biplanetory gear according to geometrical representation of the linear velocity vector by the wheels diameters.

$$
\begin{aligned}
& u_{16}=2 \cdot \frac{d_{2} \cdot\left(d_{1}+d_{2}\right) \cdot\left(d_{4}+d_{5}+d_{8}\right)}{d_{1} \cdot d_{5} \cdot d_{8}}- \\
& -\frac{d_{2} \cdot\left(d_{1}+d_{2}+d_{6}\right)}{d_{1} \cdot d_{5}}+\frac{d_{1}+d_{2}}{d_{1}}
\end{aligned}
$$

The result formulas make it possible to accomplish kinematic research and estimate the influence of geometric parameters on transmission ratio of doubleflow PG.

\section{Conclusion}

The approach is developed and research of kinematics of PG with closed nonparallel power flows is accomplished on the approach basis. Analytical expressions for determination of transmission ratio of $\mathrm{PG}$ advanced types are obtained.

The represented approach develops graphic method of PG research and appears as basis for power analysis of PG closed types.

\section{References}

1. A.S. Ivanov, V.M. Zyablikov, M.V. Fomin and others, Vestnik mashinostroenija 4, 15 (2004)

2. J. Drewniak, P. Garlicka, A., Scientific Journal of Silesian University of Technology. Series Transport. 91, 5 (2016).

3. A.A. Chirkov, Metro and tunnels 2, 12 (2009)

4. V. Argeşanu, I.S. Borozan, I. Maniu, R.M. Kulcsar, M. Jula., International journal of systems applications, engineering \& development 8, 277 (2014)

5. A.S. Ivanov., M.V. Fomin, M.M. Ermolaev and others, Vestnik mashinostroenija 8, 22 (2012)

6. Ja.A. Andreeva, I.A. Zhukov, Industrial Engineering 22, 12 (2012)

7. A.S. Ivanov, M.V. Fomin, M.M. Ermolaev, Higher educational establishment news. Industrial Engineering 13, 37 (2012) 